\title{
Identification of Fusarium commune, the Causal Agent of Postharvest Zinnia Meltdown Disease in Tennessee
}

\author{
Ravi Bika ${ }^{1}$ and Fulya Baysal-Gurel ${ }^{1}$
}

ADDITIONAL INDEX WORDS. bend stem, cut flower, first report, ornamental, postharvest vase life, Zinnia elegans

\begin{abstract}
SuMmARY. The cut flower growers of the eastern and southern United States are threatened with postharvest meltdown of zinnia (Zinnia elegans), which reduces yield and income as well as limiting opportunities for production expansion. Disease symptoms such as bending of the stem just below the flower were visually apparent on zinnia cut flowers. The objective of this study was to identify the causal agent related to zinnia meltdown. A total of 20 symptomatic zinnia cut flower stems were collected from Tennessee. Several Fusarium-like colonies with micro and macroconidia were isolated from the base and bend area of stems on potato dextrose agar (PDA) and Fusarium-selective media. Morphological characterization, polymerase chain reaction, and sequencing of three representative isolates, FBG2020_198, FBG2020_199, and FBG2020_201, were conducted to confirm pathogen identification. The sequence identity of the isolates was $>99 \%$ identical to Fusarium commune, and a combined phylogenetic tree grouped the isolates with the clade of $F$. commune from different host and geographical locations. To accomplish Koch's postulates, a pathogenicity test was performed on 'Benary's Giant Golden Yellow', 'Benary's Giant Lime', and 'Benary's Giant Pink' zinnia plants at vegetative (2 weeks after transplantation) or flower bud stage ( 1 month after transplantation) by drench, stem injection, and foliar spray of conidial suspension $\left(1 \times 10^{5}\right.$ conidia $\left./ \mathrm{mL}\right)$. Similar symptoms of meltdown (floral axis bending just below the flower) were observed on inoculated zinnia cultivars 2 days after harvesting. Fusarium commune was reisolated from the infected flower stems of all three cultivars but not from the noninoculated zinnia flower stems. Zinnia stem colonization by $F$. commune was statistically similar in all three tested cultivars regardless of plant growth stage and method of inoculation. This study confirms $F$. commune as being the causal agent of postharvest zinnia flower meltdown issue in Tennessee. In the future, possible sources of pathogen will be screened, and disease management recommendations will be developed.
\end{abstract}

$\mathrm{T}$ The U.S. floriculture trade has an estimated wholesale value of $\approx \$ 4.77$ billion in sales annually with the production area covering $\approx 19,768$ acres [U.S. Department of Agriculture (USDA), National Agriculture Statistic Service (NASS), 2019]. The cut flower industry comprised $8 \%$ of the total floriculture trade with annual sales of $\$ 375$ million in 2018, which is a slight increase $(\approx 0.2 \%)$ from 2015 (USDA-NASS, 2019).

Specialty cut flowers include all flower, foliage, stems, and fruits other than roses (Rosa sp.), chrysanthemums (Chrysanthemum sp.), and carnations (Dianthus sp.), which are known as traditional cut flowers (Gast and Stevens, 1993; Yue and Hall, $2010)$. In the past few years, the production of specialty cut flowers has grown in the United States because it is difficult to transport specialty flowers to long-distance markets (Ortiz et al., 2012; Yue and Hall, 2010); thus, flowers must be grown regionally to make them available in local markets. Granitz (2014) reported that $67 \%$ of specialty cut flower growers in North Carolina experienced an increase in demand for cut flowers, predominantly locally produced flowers. Zinnia (Zinnia elegans) is one of the top five most grown specialty cut flowers in North America (Loyola et al., 2019). It is a widely cultivated ornamental crop in the United States because of its diversity in floret morphology and color, plant height as well as habit, which has made the development of different cultivars suitable for cut flowers and flowerbeds possible (Szopińska, 2016).

Unfortunately, the incidence of disease or disorder, both in pre- and postharvest conditions, often reduce the quality of zinnia flowers, causing economic losses to growers. In recent years, the zinnia meltdown (flower stem bend and collapse) has become more problematic. According to the survey report conducted by Loyola et al. (2019), zinnia meltdown is one of the most significant postharvest problems in the zinnia cut flower market. The main problem with zinnia meltdown is that it may not be detected in field conditions; the flower exhibits the meltdown symptoms 1 to $2 \mathrm{~d}$ after harvesting. In addition, zinnia meltdown may prevail for some years and be absent in other years (Dole et al., 2017). The causal agent behind the meltdown was unknown; however, it was suspected to be microbial colonization of vascular tissue. Therefore, identification of the cause of this enigmatic postharvest zinnia meltdown is critical to develop management recommendations.

The objective of this study was to identify the causal agent responsible for the zinnia meltdown in postharvest conditions. Therefore, we used morphological, molecular, and phylogenetic analysis as well as pathogenicity test for the definitive identification of the pathogen causing zinnia meltdown in Tennessee.

\section{Materials and methods Survey, isolate collection, and culturing}

A survey was developed using online software (SurveyMonkey; SVMK, San Mateo, CA) in 2017 and

\begin{tabular}{llll}
\hline $\begin{array}{l}\text { Units } \\
\text { To convert U.S. to SI, } \\
\text { multiply by }\end{array}$ & U.S. unit & SI unit & $\begin{array}{l}\text { To convert SI to U.S., } \\
\text { multiply by }\end{array}$ \\
\hline 1233.4819 & acre-ft & $\mathrm{m}^{3}$ & 0.0008 \\
29,574 & fl oz & $\mu \mathrm{L}$ & $3.3814 \times 10^{-5}$ \\
29.5735 & fl oz & $\mathrm{mL}$ & 0.0338 \\
2.54 & inch $(\mathrm{es})$ & $\mathrm{cm}$ & 0.3937 \\
25.4 & inch $(\mathrm{es})$ & $\mathrm{mm}$ & 0.0394 \\
1 & $\operatorname{micron}(\mathrm{s})$ & $\mu \mathrm{m}$ & 1 \\
$\left({ }^{\circ} \mathrm{F}-32\right) \div 1.8$ & ${ }^{\circ} \mathrm{F}$ & ${ }^{\circ} \mathrm{C}$ & $\left({ }^{\circ} \mathrm{C} \times 1.8\right)+32$
\end{tabular}


advertised through the official page of the Association of Specialty Cut Flower Growers. The purpose of the survey was to collect information on the postharvest zinnia meltdown issue and identify the volunteer cut flower growers for sample collection. A total of 20 harvested zinnia stems with flowers exhibiting bend flower stem, including 'Benary's Giant Golden Yellow', 'Benary's Giant Lime', and 'Benary's Giant Pink', were collected in June 2017 from a private flower farm located in Lincoln County, TN. The obtained samples were first examined under light microscopy (BX50; Olympus, Center Valley, PA). Small sections of zinnia stem from cut base and bend area were plated on PDA (Sigma-Aldrich, St. Louis, MO) and Fusarium-selective media after surface sterilization with $70 \%$ ethanol (SigmaAldrich). Fusarium-selective medium was prepared according to the protocol described by Tio et al. (1977). At least four zinnia stem pieces were plated in each petri dishes for each sample. The plates were incubated for 5 to $7 \mathrm{~d}$ at $21{ }^{\circ} \mathrm{C}, 60 \%$ relative humidity $(\mathrm{RH})$, and 12-h fluorescent light and dark cycle.

\section{Morphological characterization}

The fungal isolates grown on PDA and Fusarium-selective medium were used for determining colony growth and pigmentation, whereas microscopic examination of the isolates was conducted after 10 to $14 \mathrm{~d}$ of growth on weak nutrient agar

Received for publication 12 Jan. 2021. Accepted for publication 8 Apr. 2021.

Published online 23 June 2021.

${ }^{1}$ Department of Agriculture and Environmental Sci ences, College of Agriculture, Tennessee State University, Otis L. Floyd Nursery Research Center, 472 Cadillac Lane, McMinnville, TN 37110

This project was funded by the Association of Specialty Cut Flower Growers Research Foundation and the National Institute of Food and Agriculture, U.S. Department of Agriculture Evans-Allen grant, under award numbers TENX-1926-CCOCP and TENX-S-1083. We thank Terri Simmons and Christina Jennings for their help with setting up the experiment and Dr. Farhat Avin for his help with molecular analysis.

Mention of trade names of commercial products in the publication is solely for the purpose of providing specific information and does not imply recommendation or endorsement by Tennessee State University.

F.B.-G. is the corresponding author. E-mail: fbaysalg@tnstate.edu.

This is an open access article distributed under the CC BY-NC-ND license (https://creativecommons. org/licenses/by-nc-nd/4.0/)

https://doi.org/10.21273/HORTTECH04795-21
[Spezieller Nährstoffarmer Agar (SNA) (Nirenberg, 1976)] at $21^{\circ} \mathrm{C}, 60 \%$ $\mathrm{RH}$, and $12 \mathrm{~h}$ of light and dark period. A small block $(2 \times 2 \mathrm{~mm})$ of SNA medium block was mounted on a slide with a drop of water and covered with a coverslip for the microscopic observation. The presence or absence, shape, and size of micro and macroconidia, chlamydospores, and phialides was examined under light microscopy (BX50). The data were recorded from 40 randomly selected micro and macroconidia, chlamydospores, and phialides, and their mean value and range were determined.

\section{Molecular analysis}

Three representative isolates (FBG2020_198, FBG2020_199, and FBG2020_201) of Fusarium species were grown on PDA medium for 10 to $14 \mathrm{~d}$, and used for molecular identification. The surface of the fungal colonies was gently scraped, and harvested mycelium was dropped into a $2-\mathrm{mL}$ centrifuge tube filled with $70 \%$ of ethanol for extraction of DNA. The fungal total DNA was extracted using PowerLyzer Ultraclean Microbial DNA Isolation Kit (MO-BIO Laboratories, Carlsbad, CA) according to the manufacturer's protocol. After the extraction of the DNA, samples were stored at $-20^{\circ} \mathrm{C}$.

A portion of the four nuclear DNA genes/regions [internal transcribed spacer (ITS), Translation Elongation Factors $1-\alpha$ (EF- $l \alpha)$, beta-tubulin (bTub), and mitochondrial small subunit ribosomal RNA (mtSSU)] were amplified using ITSI (5'-TCCGTAGGTGAACCTGCGG- $\left.3^{\prime}\right)$ and ITS4 ( $5^{\prime}$-TCCTCCGCTTATTGATATGC- $3^{\prime}$ ), EFl (5'-ATGGGTAAGGARGACAAGAC$\left.3^{\prime}\right)$ and EF-2 (5'-GGARGTACCAGTSATCATGTT- $\left.3^{\prime}\right)$, TIF ( $5^{\prime}$-AACATGCGTGAGATTGTAAGT- $3^{\prime}$ ) and T222 (5'-GACCGGGGAAACGGAGACAGG- $3^{\prime}$, and MSI (5'-CAGCAGTGAGGAATATTGGTCAATG$\left.3^{\prime}\right)$ and MS2 (5'-CGGATCATCGAA TTAAATAACAT- $\left.3^{\prime}\right)$, respectively $(\mathrm{Li}$ et al., 1994; O'Donnell and Cigelnik, 1997; O'Donnell et al., 1998; Stefańczyk et al., 2016; White et al., 1990). A $25-\mu \mathrm{L}$ polymerase chain reaction (PCR) volume was prepared that contained $2.5 \mu \mathrm{L}$ of each primer adjusted at 10 $\mu \mathrm{M}$ concentration (forward and reverse), $12.5 \mu \mathrm{L}$ of PCR green master mix containing TaqDNA polymerase, dNTPs, $\mathrm{MgCl}_{2}$ and reaction buffer (GoTaq MasterMix; Promega Corp., Madison, WI), $5.5 \mu \mathrm{L}$ nuclease free water, and $2.0 \mu \mathrm{L}\left(5 \mathrm{ng} \cdot \mu \mathrm{L}^{-1}\right) \mathrm{DNA}$. PCR amplification was carried out by using a thermal cycler (C1000 Touch; Bio-Rad Laboratories, Hercules, CA) programmed at $94{ }^{\circ} \mathrm{C}$ for $5 \mathrm{~min}$ for initial denaturation; $94^{\circ} \mathrm{C}$ for $40 \mathrm{~s}$ for denaturation; $50^{\circ} \mathrm{C}$ for $\mathrm{mtSSU}, 55^{\circ} \mathrm{C}$ for ITS, and $60^{\circ} \mathrm{C}$ for Ef-l $\alpha$ and bTub annealing temperature and $72^{\circ} \mathrm{C}$ for $40 \mathrm{~s}$ for extension (32 cycles); and $72{ }^{\circ} \mathrm{C}$ for $5 \mathrm{~min}$ for the final extension. The PCR products were partitioned using gel electrophoresis in $1 \%$ agarose in IX TBE buffer prestained with GelRed nucleic acid (Biotium, Fremont, CA). The bands of PCR products were visualized under Gel Doc EZ imager (Bio-Rad Laboratories). The PCR products were purified using the Wizard SV Gel and PCR CleanUp System (Promega Corp.) and sent to GenHunter Corp. in Nashville, TN, for Sanger sequencing.

Revision of individual DNA sequences was done using the Chromas Lite version 2.01 software (Technelysium, South Brisbane, Australia) and the sequences were aligned and edited using MEGA 6.0 software (Tamura et al., 2013). The highly matching sequence of ITS, EF- $1 \alpha$, b-Tub, and $\mathrm{mtSSU}$ genes were retrieved from the National Center for Biotechnology Information (NCBI, Bethesda, MD) and used as references. Then the sequences of representative isolates were deposited in the NCBI Web site. In addition, the phylogenetic tree was constructed using the neighbor-joining method. Bootstrap phylogeny analysis was done with 500 replications to statistically test the stability of clade.

\section{Pathogenicity test}

The plant materials. Seeds of 'Benary's Giant Golden Yellow', 'Benary's Giant Lime', and 'Benary's Giant Pink' zinnia were purchased from a commercial seed company (Johnny's Selected Seeds, Fairfield, ME). Seeds were sown in a 72 -cell plug flat filled with potting mix containing Canadian sphagnum peat ( $32 \%$ to $40 \%)$, vermiculite, and perlite (Growmix \#2; Morton's Horticultural Products, McMinnville, $\mathrm{TN})$. Then, the seeded zinnia tray was placed in a climate-controlled germination chamber (Stability chamber; 
Norlake Scientific, Hudson, WI) at $27^{\circ} \mathrm{C}$ for $3 \mathrm{~d}$ and then to $21^{\circ} \mathrm{C}$; $\mathrm{RH}$ was adjusted to $95 \%$ and $24 \mathrm{~h}$ fluorescent light until germination.

When zinnia seedlings started to show the first true leaves, they were transplanted in 10-cm-square pots filled with potting mix containing Canadian sphagnum peat (32\% to $40 \%$ ), vermiculite and perlite (Growmix \#2, Morton's Horticultural Products). The potting mix was first sterilized with an electric soil sterilizer tool (Soil sterilizer model SS-30; Pro-Grow Supply Corp., Brookfield, WI) at a temperature of $85^{\circ} \mathrm{C}$ for $2 \mathrm{~h}$. The transplanted zinnia seedlings were grown in a greenhouse facility at Tennessee State University Otis L. Floyd Nursery Research Center (TSUNRC) in McMinnville, TN. Irrigation was applied twice per day for 2 min using micro bubbler emitters (Micro sprays; Rain Bird, Azusa, CA) mounted on short stakes on the greenhouse benches. The zinnia seedlings did not receive any fertilizers, micronutrients, pesticides, or fungicides during the entire experiment period. In pathogenicity test 1 , the average greenhouse temperature and $\mathrm{RH}$ for Aug., Sept., Oct., and Nov. 2019 were $23.3^{\circ} \mathrm{C}$ and $95.5 \%, 21.1^{\circ} \mathrm{C}$ and $95.4 \%, 23.2^{\circ} \mathrm{C}$ and $87.6 \%$, and $17^{\circ} \mathrm{C}$ and $85.6 \%$, respectively. Similarly, average greenhouse temperatures and $\mathrm{RH}$ during pathogenicity test 2 for May, June, July, and Aug. 2020 were $23.2^{\circ} \mathrm{C}$ and $68 \%$, $23.8^{\circ} \mathrm{C}$ and $95.3 \%, 24.7^{\circ} \mathrm{C}$ and $99.3 \%$, and $23.7^{\circ} \mathrm{C}$ and $99 \%$, respectively.

Fungal INOCULUM PREPARATION. The FBG2020_198 isolate of Fusarium commune collected from the zinnia samples exhibiting the meltdown issue was grown on PDA medium at room conditions $\left(21^{\circ} \mathrm{C}, 60 \% \mathrm{RH}\right)$ with $12 \mathrm{~h}$ fluorescent light. The conidial suspension was prepared by flooding 2- to 3-week-old F. commune culture with sterilized distilled water. The obtained suspension of $F$. commune was filtered through cheesecloth and diluted using sterilized, distilled water. Then, $10 \mu \mathrm{L}$ of conidial suspension was withdrawn and dropped on a hemocytometer (Hausser Scientific, Horsham, PA) for determination of conidial concentration; conidia were counted using light microscopy (BX50). The final concentration of $F$. commune conidia was adjusted to $1 \times 10^{5}$ conidia $/ \mathrm{mL}$ using the formula $\mathrm{C}_{1} \mathrm{~V}_{1}=\mathrm{C}_{2} \mathrm{~V}_{2}$, where $\mathrm{C}_{1}=$ initial concentration of conidia from hemocytometer reading, $\mathrm{V}_{\mathrm{l}}=$ volume of spore suspension required to make final volume of desired concentration of conidia, $\mathrm{C}_{2}=$ desired concentration of conidia, and $\mathrm{V}_{2}=$ final desired volume of conidial suspension.

INOCULATION METHOD AND PATHOGENICITY TEST DESIGN. The test was carried out at the TSUNRC using 'Benary's Giant Golden Yellow', 'Benary's Giant Lime', and 'Benary's Giant Pink' zinnia plants. The first trial was conducted from 19 Aug. to 23 Nov. 2019 and the second trial from 5 May to 20 Aug. 2020. In the pathogenicity test, two separate sets of trials were conducted to study the effect of timing of the inoculations: vegetative stage (2 weeks after transplantation) and flower bud initiation stage (1 month after transplantation). Three different inoculation methods were tested for each plant growth stage: drench, stem injection, and foliar spray.

In the drench method, $25 \mathrm{~mL}$ of F. commune conidial (FBG2020_198 isolate) suspension was applied to the potting mix of 10 zinnia plants using a measuring beaker while 10 of the control zinnia plants received the same amount of sterilized distilled water. The amount of solution to be drenched in a zinnia pot was determined by pour-through test (100 $\mathrm{mL} / \mathrm{pot}$ ); the solution holding capacity was calculated by subtracting the total infiltrated volume from total initial volume drenched. The same inoculum level was used for both plant growth stage experiments (vegetative stage and flower bud initiation stage).

In the stem injection method, 30 $\mu \mathrm{L}$ of $F$. commune (FBG2020_198 isolate) conidial suspension was injected into each zinnia stem using a 1 $\mathrm{mL}$ syringe (Sub-Q; Becton Dickinson \& Co., Franklin Lakes, NJ) with a disposable needle. The conidial suspension was released into a minute perforation while taking out the needle from the zinnia stem and three perforations were made along zinnia stem: $1.0,1.5$, and $2.0 \mathrm{~cm}$ up from the base (substrate level). The disposable needles from the syringes were replaced with new ones between inoculation of each zinnia plant. Each control zinnia plant received the same amount of sterilized, distilled water injected in the same manner. Both the inoculated and control groups had 10/10 zinnia plants each.
In the foliar spray method, 10 zinnia plants were sprayed with conidial suspension of $F$. commune (FBG2020_ 198 isolate) containing $0.1 \%(\mathrm{w} / \mathrm{v})$ nonionic surfactant (Tween 20; SigmaAldrich) until runoff using handheld sprayer, whereas 10 control zinnia plants were sprayed with sterilized, distilled water containing $0.1 \%(\mathrm{w} / \mathrm{v})$ nonionic surfactant (Tween 20).

The experiment was arranged in a completely randomized block design with 10 zinnia plants per each variable (cultivar $\times$ plant growth stage $\times$ inoculation method) and repeated twice. Each inoculated variable had a corresponding control group (i.e., 18 inoculated and 18 noninoculated group); there were a total of 360 zinnia plants in each experiment. The zinnia flowers, along with their corresponding stems, were harvested when outer petals of the flowers were fully expanded. The zinnia plants were harvested at 2 $\mathrm{cm}$ above the potting mix surface. Harvested zinnia stems with flowers were maintained in $900-\mathrm{mL}$ beakers filled with tap water and displayed at $21{ }^{\circ} \mathrm{C}, 60 \% \mathrm{RH}$, and $24 \mathrm{~h}$ fluorescent light using a completely randomized design.

OBSERVATION, RE-ISOLATION OF PATHOGEN, AND STATISTICAL ANALYSIS. The observation on the presence and absence of postharvest zinnia meltdown was made for 1 week. To complete the Koch's postulates, re-isolation of the pathogen was conducted from both inoculated and control zinnia stems at a specific distance from the potting mix level (from each centimeter of zinnia stem up to $36 \mathrm{~cm}$ ) after surface sterilization of the exterior portions of the cut stems with $70 \%$ ethanol. Tissue imprinting of the sliced stem surface of each stem piece was done on Fusarium-selective medium in square petri dishes with grid lines at the bottom $(10 \mathrm{~cm} \times 10 \mathrm{~cm} \times 15 \mathrm{~mm}$ square petri dish with the grid; VWR, Radnor, PA) and incubated for 1 week in laboratory ambiance $\left(21^{\circ} \mathrm{C}, 60 \%\right.$ $\mathrm{RH}$, and $12 \mathrm{~h}$ of fluorescent light). The length of zinnia stem colonized by the $F$. commune was determined by counting $F$. commune colonies on each grid in a square petri dishes (each small grid in a square petri dishes represents the stem length of $1 \mathrm{~cm}$ ).

The length of zinnia stem colonized by $F$. commune was compared among cultivars, plant growth stage, 
Table 1. National Center for Biotechnology Information (NCBI, Bethesda, MD) GenBank accession numbers of the representative isolates of Fusarium commune isolated from zinnia cut flower stem in Tennessee. The internal transcribe spacer (ITS), elongation factor $1-\alpha($ EF- $1 \alpha)$, beta-tubulin (b-Tub), and mitochondrial small subunit ribosomal RNA (mtSSU-rRNA) genes of F. commune were amplified using ITS1/ITS4, EF1/EF-2, T1F/T222, and MS1/MS2 primer sets, respectively.

\begin{tabular}{lllll}
\hline & \multicolumn{4}{c}{ Region } \\
\cline { 2 - 5 } Isolate & ITS & EF-1 $\boldsymbol{\alpha}$ & b-Tub & mtSSU-rRNA \\
\hline FBG2020_198 & MT973967 & MW020579 & MW020583 & MW349593 \\
FBG2020_199 & MW018368 & MW020577 & MW011211 & MW349594 \\
FBG2020_201 & MW019507 & MW020578 & MW020584 & MW349595 \\
\hline
\end{tabular}

and inoculation methods. SAS software (version 9.4 for Windows; SAS Institute, Cary, NC) was used to run statistical analysis of data, and Microsoft Excel for Microsoft 365 MSO (version 16.0 for Windows; Microsoft, Redmond, WA) was used for the graphical representation of data. Analysis of variance (ANOVA) was performed using the generalized linear mixed model procedure (PROC GLIMMIX) assuming Poisson distribution with a log link to partition variance in length of zinnia stem colonization into sources attributable to treatment and error. Treatment means were separated using Tukey's Studentized range test at the $5 \%$ level of significance. The data sets obtained from two repeated experiments were analyzed in ANOVA to check whether the variable between the experiments was significant or not. The data were combined if the variability in two experiments was not significant $(\alpha=$ $0.05)$, otherwise analyzed separately.

\section{Results \\ Growers survey}

In total, 29 cut flower grower responses were received from 17 U.S. states: Connecticut (1), Georgia (3), Illinois (2), Iowa (1), Louisiana (1), Maine (1), Maryland (1), Massachusetts (1), Mississippi (2), New Jersey (4), New York (1), North Carolina (3), Ohio (2), Tennessee (2), Texas (1), Utah (1), and Virginia (1) and also Ontario, Canada (1), all of which were concerned about the zinnia meltdown issue. More than half of the respondents $(58.6 \%)$ reported the zinnia meltdown somewhat reduced salable quantity or quality of their zinnia cut flowers and $10 \%$ of the respondents reported that zinnia meltdown caused a major reduction on quality and quantity of salable zinnia cut flowers (data not shown). According to the survey results, 'Benary's Giant' was the most susceptible cultivar to the zinnia meltdown issue. A total of 20 infected zinnia samples were collected from Lincoln County, TN, showing the stem bend just below the flower axis. In an advanced level of infection, stem rot in the area of the bend was apparent on infected zinnia plants.

\section{Morphology and molecular analysis}

The colony color of FBG2020_198, FBG2020_199, and FBG2020_201 isolates showed fluffy white-creamy or white-violet aerial mycelium growth and dark violet pigmentation on the reverse when grown on PDA medium, and white-purplish, pink, cottony, delicate aerial mycelium growth when grown on Fusarium-selective medium. Numerous micro and macroconidia were visible after 2 to 3 weeks of incubation and mycelium with septa was observed under light microscopy. Microconidia were aseptate, ovate to kidney-shaped, and were dispersed singly, measuring an average of $9.5 \times 2.5 \mu \mathrm{m}$ (range: 4.5 to $15.5 \times 2.0$ to $3.8 \mu \mathrm{m})$.

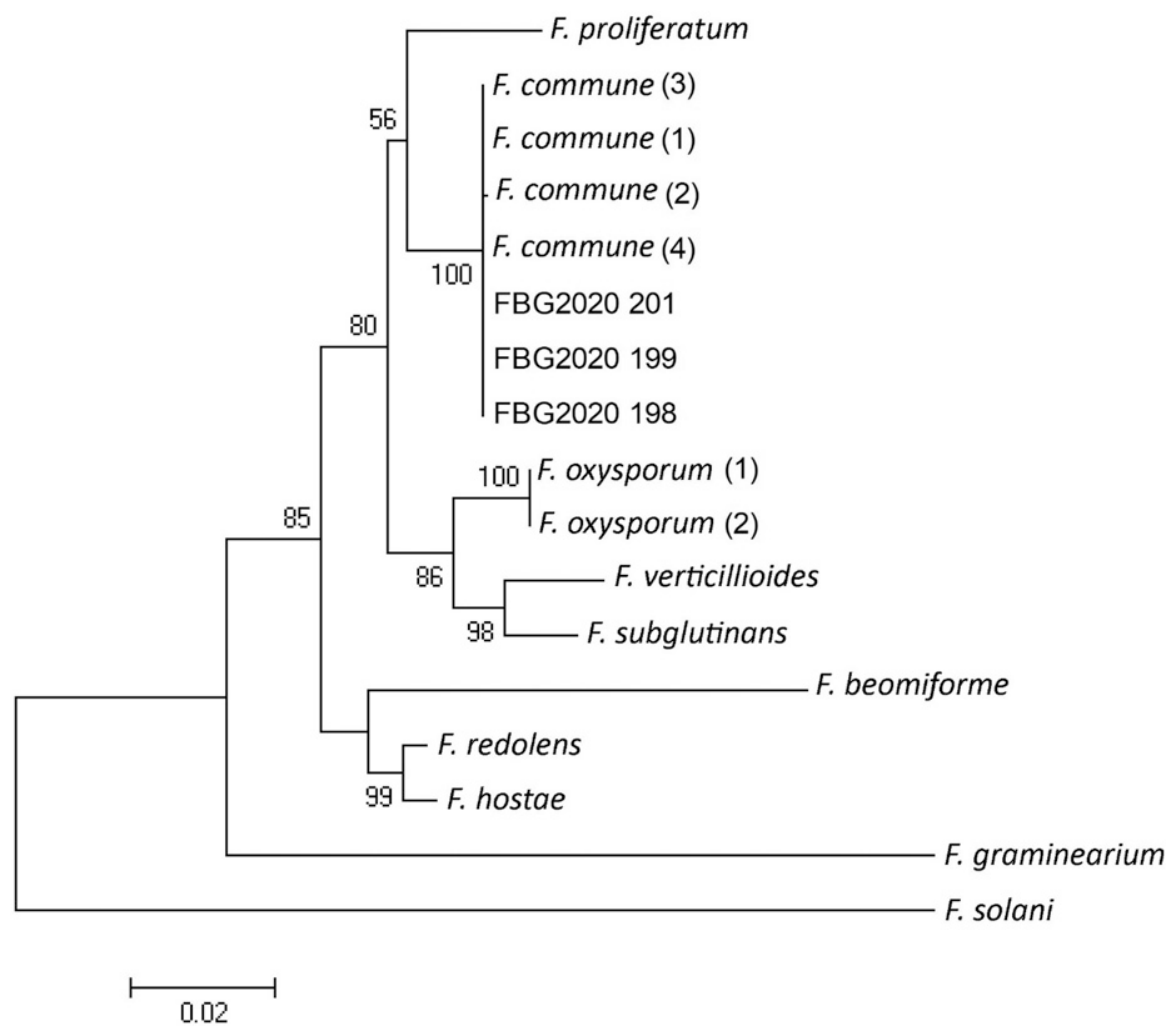

Fig. 1. Neighbor-joining phylogenetic tree based on the combined analysis of internal transcribe spacer (ITS), elongation factor $1-\alpha(E F-1 \alpha)$, beta-tubulin (b-Tub), and mitochondrial small subunit ribosomal RNA (mtSSU-rRNA) gene sequences. Numbers close to the branch nodes indicate 500 replications of bootstrap test and the "FBG" codes refer to the isolate identity used in this study. The accession numbers of GenBank sequences that were used as the reference material for all four genes are provided in Supplemental Table 1. The sequence of Fusarium graminearum and Fusarium solani were used as an outgroup. The bar indicates a distance of $\mathbf{0 . 0 2}$ nucleotide substitution per site. 
Macroconidia were curved to fusiform or somewhat straight with a sharp edge at each end, having one, two, and three septa; the three-septate conidia were most abundantly formed, measuring an average of $31.6 \times 3.7$ $\mu \mathrm{m}$ (range: 20.7 to $39.8 \times 2$ to $5.1 \mu \mathrm{m})$. The chlamydospores were smooth-walled and globose in shape and measured an average of $8.3 \times 7.8$ $\mu \mathrm{m}$ in diameter (range: 4.0 to $11.7 \times$ 3.9 to $11.5 \mu \mathrm{m}$ ). The chlamydospores were produced individually or in pairs and presented intercalary or terminal in hyphae. The presence of mono and polyphialides were also observed in culture grown on SNA medium. The phialides of conidiophores were cylindrical and measured from 12 to $40 \mu \mathrm{m}$ in length and 1.6 to $3.5 \mu \mathrm{m}$ in width. The colony pigmentation, appearance, and shape of micro- and macroconidia of the isolates derived from zinnia stems were similar to the morphological characteristics of $F$. commune described by Husna et al. (2020), Skovgaard et al. (2003), and Xi et al. (2019).

The amplified PCR products using ITS, EF- $1 \alpha$, b-Tub, and $\mathrm{mtSSU}$ regions were sequenced and the NCBI BLAST results showed $>99 \%$ identity with the sequences of $F$. commune (GenBank accession no.: MT2108 82 for ITS, KX215081 for EF-l $\alpha$, AY329043 for b-Tub, MH7l6811 for $\mathrm{mtSSU}$ genes/regions). The consensus sequences of representative isolates were deposited in the NCBI GenBank and accession numbers were listed (Table 1). Based on the molecular identification, the causal organism of the zinnia meltdown issue was identified as F. commune.

A combined phylogenetic tree for all genes (ITS, EF-l $\alpha$, b-Tub, and $\mathrm{mtSSU}$ ) was constructed to validate the identification of $F$. commune. The phylogenetic analysis grouped the isolates of zinnia from this study (FBG2020_198, FBG2020_199, and FBG2020_201) within the clade of $F$. commune originating from a wide range of other hosts in different geographical locations worldwide (Fig. 1).

\section{Pathogenicity test}

The harvested zinnia cultivars (Benary's Giant Golden Yellow, Benary's Giant Lime, and Benary's Giant Pink) exhibited meltdown symptoms (i.e., bending of the stem just below the flower axis) after 2 to $3 \mathrm{~d}$ of postharvest vase life. All three cultivars of zinnia showed the meltdown issue regardless of the plant growth stage and method of inoculation. The control zinnia cultivars did not show any bend stem symptoms. Re-isolation of $F$. commune was performed through tissue imprinting for each $1 \mathrm{~cm}$ length of zinnia stem on Fusarium-selective medium. After $7 \mathrm{~d}$ of incubation, white or white-violet cottony mycelium growth was observed in square petri dishes with grid lines. The morphology of the pathogen isolated on the Fusarium-selective medium was identical to the original isolate. free and $F$. commune was not isolated from their stems.

We observed that there was significant interaction between exper All control plants remained symptom-

iment and variables (cultivar $\times$ plant growth stage $x$ inoculation method) for length of stem colonized by $F$. commune $(\mathrm{F}=2.80, P=0.002)$, so data were analyzed within the experiments separately. From the tissue imprinting result of pathogenicity tests 1 and 2, we observed the significant interaction among cultivar, plant growth stage, and method of inoculation in colonizing the zinnia stem by $F$. commune [pathogenicity test $\mathrm{l}: \mathrm{F}=3.23$, $P<0.001$; pathogenicity test $2: \mathrm{F}=$ 4.35, $P<0.001$ (Figs. 2 and 3)]. The plant growth stage and inoculation methods did not show any statistical difference in the colonization of zinnia stem within the cultivars in both pathogenicity tests. However, 'Benary's Giant Lime' inoculated by stem injection at the vegetative stage had significantly

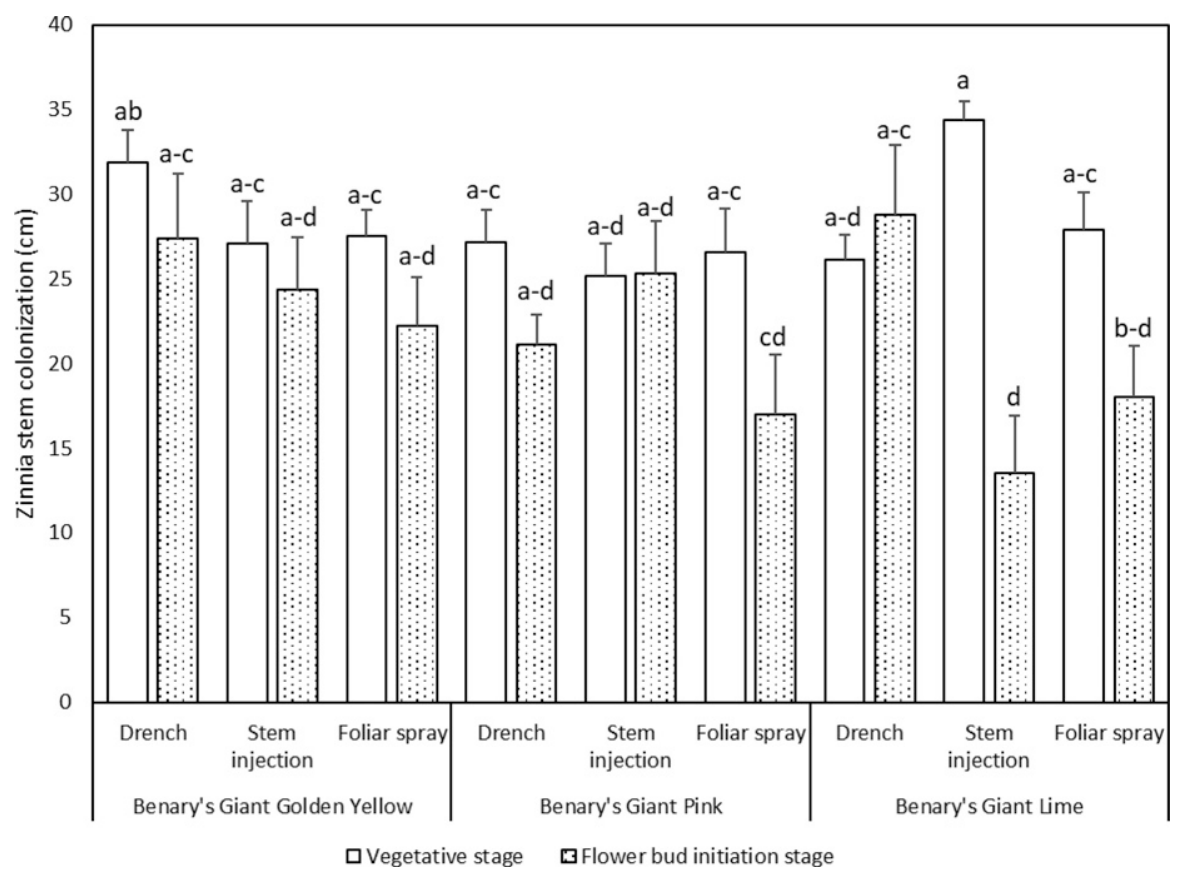

Fig. 2. Pathogenicity of Fusarium commune and response of 'Benary's Giant Golden Yellow', 'Benary's Giant Lime', and 'Benary's Giant Pink' zinnia plants after inoculation with Fusarium commune conidial suspension $\left(1 \times 10^{5}\right.$ conidia/ $\mathrm{mL}$ ) in pathogenicity test 1 . The zinnia plants were inoculated with drench, stem injection, and foliar spray method at 2 weeks and 1 month after transplantation. The zinnia stems with flower were harvested and displayed in a normal room condition. The zinnia stem tissue was imprinted on Fusarium-selective medium in a square petri dishes with grid lines after 1 week of postharvest vase life. Each small square formed by grid lines represents the $1-\mathrm{cm}$ length of zinnia stem. The presence of $F$. commune was observed in each small square in the petri dish and length of stem colonization was determined by counting the small square with $F$. commune growth. The values are the mean of 10 replications of each variable (cultivar $\times$ plant growth stages $\times$ methods of inoculation). Letters on top of the bar indicate significant difference in length of zinnia stem colonization by $F$. commune when compared among cultivars, plant growth stage, and inoculation method based on the Tukey's Studentized range test method for multiple comparison adjustment of least square means $(F=3.23, P<0.001)$. No stem colonization was observed in control group, so was not presented in the figure; 1 $\mathrm{cm}=0.3937$ inch . 


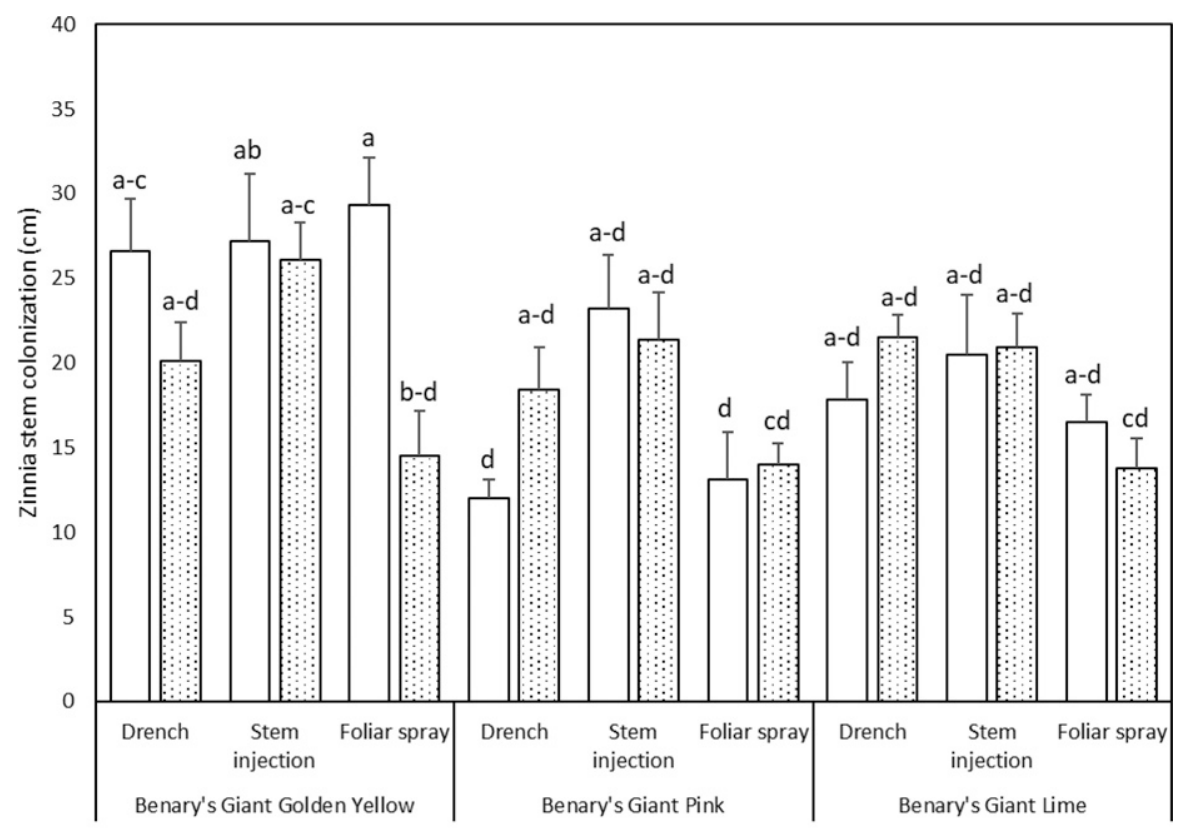

$\square$ Vegetative stage $\square$ Flower bud initiation stage

Fig. 3. Pathogenicity of Fusarium commune and response of 'Benary's Giant Golden Yellow', 'Benary's Giant Lime', and 'Benary's Giant Pink' zinnia plants after inoculation with $F$. commune conidial suspension $\left(1 \times 10^{5}\right.$ conidia $\left./ \mathrm{mL}\right)$ in pathogenicity test 2 . The zinnia plants were inoculated with drench, stem injection, and foliar spray method at 2 weeks and 1 month after transplantation. The zinnia stems with flower were harvested and displayed in a normal room condition. The zinnia stem tissue was imprinted on Fusarium-selective medium in a square petri dishes with grid lines after 1 week of postharvest vase life. Each small square formed by grid lines represents the $1-\mathrm{cm}$ length of zinnia stem. The presence of $F$. commune was observed in each small square in the petri dish and length of stem colonization was determined by counting the small square with $F$. commune growth. The values are the mean of 10 replications of each variable (cultivar $\times$ plant growth stages $\times$ methods of inoculation). Letters on top of the bar indicate significant difference in length of zinnia stem colonization by $F$. commune when compared among cultivars, plant growth stage, and inoculation method based on the Tukey's Studentized range test method for multiple comparison adjustment of least square means $(\mathrm{F}=4.35, P<0.001)$. No stem colonization was observed in control group, so was not presented in the figure; $1 \mathrm{~cm}=0.3937 \mathrm{inch}$.

longer length of stem colonization by F. commune than stem injection at the flower bud initiation stage in pathogenicity test 1 (Fig. 2). Similarly, in pathogenicity test 2 'Benary's Giant Golden Yellow' inoculated at vegetative stage using foliar spray inoculation method had significantly longer stem colonization than inoculated at flower bud initiation stage by foliar spray method (Fig. 3).

\section{Discussion}

The morphological study, sequence data, and phylogenetic analysis determined that $F$. commune is the causal agent of zinnia meltdown in Tennessee. Previously, several Fusarium species (Fusarium avenaceum, Fusarium equiseti, Fusarium culmorum, Fusarium oxysporum, and Fusarium clade, and clearly distinct from F. oxysporum. In addition, all three isolates from Tennessee from our study were grouped in the same $F$. commune clade with high bootstrap value $(100 \%)$, as there was no sequence difference among them.

Fusarium commune is a vascular colonizing and root rot pathogen and has been isolated from white pine ( $\mathrm{Pi}$ nus strobus), douglas fir (Pseudotsuga menziesii), carnation (Dianthus caryophyllus), rice (Oryza sativa), corn (Zea mays), carrot (Daucus carota), and horseradish (Armoracia rusticana) (Husna et al., 2020; Leon, 2015; Skovgaard et al., 2003). The typical meltdown observed in zinnia cut flowers in postharvest conditions might have been due to vascular colonization, because $F$. commune was isolated from different lengths of zinnia stem at the end of the pathogenicity tests. The microconidia of $F$. commune may enter a plant through natural openings and wounds and reach the xylem vessels where they grow and produce numerous microconidia. The microconidia may form cell clusters in vascular tissue, partially hindering the xylem vessel entrance, reducing water uptake, and ultimately, causing stem vascular blockage that can lead to bending of the stem below the flower (meltdown) during the postharvest vase life. Burdett (1970) observed the "bend neck" problem in cut rose flowers due to the blockage in xylem vessels, which restricted flow of water. It has been proposed that vessel blockage could be due to a) induction of plant to secrete defense material during pathogen invasion that may cause the restriction in flow of water; b) secretion of different enzyme or protein by pathogen that can degrade or change cell wall to xylem clogging substance (Burdett, 1970). In Fusarium-infected plants, pectic substances, gum, and polysaccharides were suspected to be present for causing the vessel plugging (Dimond, 1955); however, the presence of these substances in $F$. commune-infected plants for causing vascular tissue blockage still requires comprehensive study. The ability of $F$. commune to produce cellulose and hemicellulose-degrading enzymes, such as glycoside hydrolases, polysaccharide monooxygenases, hemicellulases, and xylanase, has been described by Huang et al. (2015).

Both pathogenicity tests showed that all zinnia cultivars inoculated 
with different methods at different plant growth stage showed the typical meltdown symptoms during postharvest vase life. This indicates that $F$. commune can infect the plants at any growth stage and through different means (e.g., soil, water, wounds) and remain inactive; it becomes aggressive once the plant is stressed (such as due to harvest or postharvest environment) and causes the postharvest meltdown of cut zinnia flowers. We observed that $F$. commune inoculated at the vegetative stage had longer length of stem colonization than inoculated at the flower bud stage. This might have been due to longer time available for $F$. commune colonization inside the zinnia stem at the vegetative stage. Similarly, 'Benary's Giant Golden Yellow' consistently showed the longer length of stem by $F$. commune in all growth stages and method of inoculation in both pathogenicity tests, indicating that it is more susceptible to postharvest meltdown than 'Benary's Giant Pink' and 'Benary's Giant Lime'.

In conclusion, the morphological, molecular, and phylogenetic analysis as well as pathogenicity studies confirmed F. commune as being the causal organism for the zinnia meltdown disease in Tennessee. There has been very limited research done in the management of $F$. commune, so it is important to adopt integrated disease management strategies (sanitation, cultural, biological, biofumigants crop, and fungicides) to prevent the incidence and infection during production. Future research will include cultivar screening to determine a response of zinnia cultivars to $F$. commune and identifying the possible sources, such as irrigation water, transplants, soil, of $F$. commune in the commercial zinnia production areas. In addition, we are still accepting zinnia samples from different states in the United States or other countries to better understand the zinnia meltdown disease. The identification of F. commune, the causal agent of zinnia meltdown, is important in the determination and implementation of effec tive management strategies.

\section{Literature cited}

Burdett, A. 1970. The cause of bent neck in cut roses. J. Amer. Soc. Hort. Sci. 95:427-431.
Dimond, A. 1955. Pathogenesis in the wilt diseases. Annu. Rev. Plant Physiol. 6:329-350.

Dole, J., R. Stamps, A. Carlson, I. Ahmad, L. Greer, and J. Laushman. 2017. Postharvest handling of cut flowers and greens, a practical guide for commercial growers, wholesalers and retailers. Assn. Specialty Cut Flower Growers, Oberlin, $\mathrm{OH}$.

Gast, K. and A. Stevens. 1993. Consumer acceptance of specialty cut flowers. HortScience 28:565.

Granitz, H.M. 2014. Improving the North Carolina cut flower industry: A production and marketing survey, field and postharvest cut flower variety evaluations, and preemergence herbicide trials on unlabeled cut flower crops. North Carolina State Univ., Raleigh, MS Thesis.

Huang, Y., P.K. Busk, and L. Lange. 2015. Cellulose and hemicellulose-degrading enzymes in Fusarium commune transcriptome and functional characterization of three identified xylanases. Enzyme Microb. Technol. 73:9-19, doi: 10.1016/ j.enzmictec.2015.03.001.

Husna, A., L. Zakaria, and N.M. Mohamed Nor. 2020. Fusarium commune associated with wilt and root rot disease in rice. Plant Pathol. 70:123-132, doi: $10.1111 /$ ppa.13270.

Leon, A.L. 2015. Quantification and determination of Fusarium commune inoculum threshold levels in douglas-fir nurseries. Washington State Univ. Pullman, PhD Diss. 6 Mar. 2021. <http://0-proquest. com.sultan.tnstate.edu/dissertations-theses/ quantification-determination-inoculumthreshold/docview/1711729928/se-2? accountid $=14275>$.

Li, K., D. Rouse, and T. German. 1994. PCR primers that allow intergeneric differentiation of ascomycetes and their application to Verticillium spp. Appl. Environ. Microbiol. 60:4324-4331.

Loyola, C.E., J.M. Dole, and R. Dunning. 2019. North American specialty cut flower production and postharvest survey. HortTechnology 29:338-359, doi: 10.21273/ HORTTECH04270-19.

Nirenberg, H. 1976. Untersuchungen über die morphologische und biologische differenzierung in der Fusarium-Sektion Liseola. Mitteilungen aus der Biologischen Bundesanstalt Für Land- und Forstwirtschaft (Berlin - Dahlem) 169:1-117.

O’Donnell, K. and E. Cigelnik. 1997. Two divergent intragenomic rDNA ITS2 types within a monophyletic lineage of the fungus Fusarium are nonorthologous. Mol. Phylogenet. Evol. 7:103-116, doi: 10.1006/mpev.1996.0376.
O’Donnell, K., H.C. Kistler, E. Cigelnik, and R.C. Ploetz. 1998. Multiple evolutionary origins of the fungus causing Panama disease of banana: Concordant evidence from nuclear and mitochondrial gene genealogies. Proc. Natl. Acad. Sci. USA 95:2044-2049, doi: 10.1073/ pnas.95.5.2044.

Ortiz, M.A., K. Hyrczyk, and R.G. Lopez. 2012. Comparison of high tunnel and field production of specialty cut flowers in the Midwest. HortScience 47:1265-1269, doi: 10.212 73/HORTSCI.47.9.1265.

Skovgaard, K., S. Rosendahl, K. O'Donnell, and H.I. Nirenberg. 2003. Fusarium commune is a new species identified by morphological and molecular phylogenetic data. Mycologia 95:630-636, doi: 10.1080/15572536.2004.11833067.

Stefańczyk, E., S. Sobkowiak, M. Brylińska, and J. Śliwka. 2016. Diversity of Fusarium spp. associated with dry rot of potato tubers in Poland. Eur. J. Plant Pathol. 145:871-884, doi: 10.1007/s10658-0160875-0.

Szopińska, D. 2016. Diseases of zinnia, p. 1-31. In: R.J. McGovern and W.H. Elmer (eds.). Handbook of florists' crops diseases. Springer, Cham, Switzerland.

Tamura, K., G. Stecher, D. Peterson, A. Filipski, and S. Kumar. 2013. MEGA6: Molecular evolutionary genetics analysis version 6.0. Mol. Biol. Evol. 30:2725-2729.

Tio, M., L. Burgess, P. Nelson, and T. Toussoun. 1977. Techniques for the isolation, culture and preservation of the fusaria. Aust. Plant Pathol. Soc. Newsl. 6:11-13, doi: 10.1071/APP9770011.

U.S. Department of Agriculture, National Agriculture Statistic Service. 2019. Floriculture crops 2018 summary. 6 June 2020. $<$ https://usda.library.cornell.edu/concern/ publications/0p0966899? locale=en $>$.

White, T.J., T.D. Bruns, S. Lee, and J. Taylor. 1990. Amplification and direct sequencing of fungal ribosomal RNA genes for phylogenetics, p. 315-322. In: M. Innis, D. Gelfand, J. Shinsky, and T. J. White (eds.). PCR protocols: A guide to methods and applications. Academic Press, San Diego, CA.

Xi, K., H.A. Haseeb, L. Shan, W. Guo, and X. Dai. 2019. First report of Fusarium commune causing stalk rot on maize in Liaoning province, China. Plant Dis. 103:773, doi: 10.1094/PDIS-09-181674-PDN.

Yue, C. and C. Hall. 2010. Traditional or specialty cut flowers? Estimating U.S. consumers' choice of cut flowers at noncalendar occasions. HortScience 45:382-386, doi: 10.21273/HORTSCI.45.3.382. 
Supplemental Table 1. National Center for Biotechnology Information (NCBI, Bethesda, MD) GenBank accession numbers for internal transcribe spacer (ITS), elongation translation factor $1-\alpha$ (EF- $1 \alpha$ ), beta-tubulin (b-Tub), and mitochondrial small subunit ribosomal RNA (mtSSU-rRNA) genes of different Fusarium species used in the phylogenetic analysis. The number in parentheses represents different isolates of Fusarium oxysporum and Fusarium commune from different geographical locations that has been amplified with ITS, EF- $1 \alpha$, b-tub, and mtSSU-rRNA genes.

\begin{tabular}{|c|c|c|c|c|}
\hline Fusarium species & ITS & EF-1 $\alpha$ & b-Tub & mtSSU-rRNA \\
\hline Fusarium graminearum & MK780228 & MG826888 & MG826888 & JQ717204 \\
\hline Fusarium solani & MG654678 & DQ247354 & KC964153 & MT383122 \\
\hline Fusarium oxysporum (1) & KX058546 & MN689546 & KP964910 & DQ831944 \\
\hline F. oxysporum (2) & MK629373 & MT630380 & KX609707 & AF250601 \\
\hline Fusarium commune (1) & MT210882 & MK952865 & MH341251 & KY439901 \\
\hline F. commune (2) & MN560034 & KX215081 & AY329043 & MH716811 \\
\hline Fusarium proliferatum & MG274295 & MT185674 & LT575130 & MN386815 \\
\hline Fusarium redolens & KF499036 & MK937112 & MT011043 & AF324281 \\
\hline Fusarium hostae & MH863067 & MT409456 & KF466440 & EF437323 \\
\hline Fusarium verticillioides & KC709665 & LS423164 & MT011054 & KX218408 \\
\hline Fusarium subglutinans & KX385059 & MN861796 & AB587057 & DQ831946 \\
\hline Fusarium beomiforme & MH862691 & MF120508 & U61544 & $\mathrm{U} 34524$ \\
\hline
\end{tabular}

